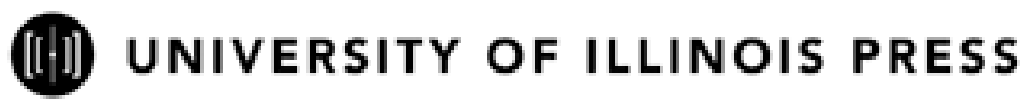 \\ the society for ethnomusicology
}

The Practice of Perception: Multi-Functionality and Time in the Musical Experiences of a Heavy Metal Drummer

Author(s): Harris M. Berger

Source: Ethnomusicology, Vol. 41, No. 3 (Autumn, 1997), pp. 464-488

Published by: University of Illinois Press on behalf of Society for Ethnomusicology

Stable URL: http://www.jstor.org/stable/852760

Accessed: 29/05/2014 15:39

Your use of the JSTOR archive indicates your acceptance of the Terms \& Conditions of Use, available at http://www.jstor.org/page/info/about/policies/terms.jsp

JSTOR is a not-for-profit service that helps scholars, researchers, and students discover, use, and build upon a wide range of content in a trusted digital archive. We use information technology and tools to increase productivity and facilitate new forms of scholarship. For more information about JSTOR, please contact support@jstor.org.

University of Illinois Press and Society for Ethnomusicology are collaborating with JSTOR to digitize, preserve and extend access to Ethnomusicology. 


\section{The Practice of Perception: Multi-Functionality and Time in the Musical Experiences of a Heavy Metal Drummer}

$\mathbf{I}^{\mathrm{n}}$ $\mathrm{n}$ this article I will argue that musical perception is best understood as a kind of practice and explore some of the broad consequences of this orientation for music research. I use the term practice in the dialectical sense elaborated by writers such as Pierre Bourdieu (1977) and Anthony Giddens (1979, 1984, 1993). In their writings, practice (or human action) has been considered as the underlying social reality from which seemingly intractable opposites such as "the individual" and "society" are derived. The central insight of practice theory is that practice is always the individual's active achievement, but that that active achievement is always constrained and enabled by past and present social contexts. In this view, "agency" (the subject's active intervention in the world) and "structure" (the order of society in which the subject is surrounded) are a duality, as inextricable as two sides of the same coin (Giddens 1979). In this paper I will apply these ideas to the issue of musical perception. Many ethnomusicologists have revealed underlying, culturally specific systems of perception in music; others have observed that the same object in perception can be experienced in different ways. My aim is to show that perception is both profoundly influenced by the perceiver's social context and nevertheless is open-ended and actively accomplished by musical participants. In short, perception is a kind of practice. ${ }^{1}$

As a case study in the practice of perception, this paper offers some tentative hypotheses to explain how a heavy metal drummer actively shifts the focus of attention among temporal levels in musical perception in order to achieve various musical goals in nightclub performance. While the

(c) 1997 by the Board of Trustees of the University of Illinois 
musical example explored in this paper is simple, the perceptual practices applied to it are not; in fact, they serve as key elements in the repertory of heavy metal perceptual practices. Although it is always difficult to abstract broad conclusions from limited ethnographic data, I believe the practices examined here may be common to rock and metal drummers in general and hope that future research will explore the applicability of these ideas to other areas of American popular music.

I will begin my examination of the data by introducing John Ziats, a heavy metal drummer, and providing background on the research project in the context of which our interviews took place. In the next section I will lay out my theoretical orientation and present the content of my interpretive dialogues with Ziats. In the following two sections I will examine Ziats's musical experiences in terms of Roman Jakobson's idea of multifunctionality and Edmund Husserl's ideas on time consciousness, respectively. I will conclude by showing how perception is a kind of practice and suggesting some of the wide avenues of ethnomusicological research opened up by this approach. As a case study in the perception of drumming, it will be best to begin this examination by looking briefly at contempory work on temporal issues.

\section{Recent Examinations of Rhythm in Music Scholarship}

In the last twenty years ethnomusicologists, music theorists, musicologists, perception psychologists, and cognitive scientists have paid increasing attention to the topic of rhythmic perception. Sophisticated research and powerful insights have emerged from this attention, and many of these insights can be enriched and developed by viewing perception as a kind of practice.

In music theory, for example, large-scale rhythmic units have become a focus of interest. While theorists disagree about whether large-scale patterns of strong and weak beats (or "hypermeters") operate as macro-level analogs of traditional meters (for example, Schachter 1980, 1987; Smyth 1990; Brower 1993), no one can doubt that the debate has revealed previously unexplored levels of structure in Western art music. Other theorists have examined complex new forms of temporal organization on smaller scales, such as Elizabeth West Marvin's discussion of rhythmic contours (1991) or John Roeder's exploration of pulse streams (1994). While many of these writers (for example, Carl Schachter) make reference to musical perception as the ultimate court of appeals for the validity of a given interpretation, none operating outside of the disciplines of cognitive science or psychology make the analysis of the act of the perception a central part of their academic method. Many powerful insights into the nature of musical 
structure have emerged from this research, but this scholarship could only be enhanced if the theorists would explore the act of musical perception by listeners in performance events, rather than undertaking decontextualized analyses of their own musical perceptions, however highly trained they might be. Apart from the occasional reference to the concrete perception of musical sound by particular listeners, the effect of much of this work is to treat music as a decontextualized musical text with autonomous musical structures. This is not to say that the musical structures explored in this way are mere fictions or that the research is without merit, but rather that the emphasis on musical structure rather than the perceiving subject obscures the subject's role in constituting those structures in experience.

By synthesizing approaches from cognitive science and psychology with the methods of music theory, other writers have come closer to grounding musical structure in the acts of the perceiving subject. Candance Brower (1993), for example, explains that substantially different kinds of processing occur in sensory, short-term, and long-term memory, and uses these basic psychological concepts to shed light on the debate about the perception of large-scale metrical structure. David Smyth (1990) applies cognitive scientific notions of top-down versus bottom-up processing to shed light on similar issues. Focusing on perception rather than the musical sound per se, this research moves us closer to grounding the study of musical structure in the living experience of listening subjects. While this research provides numerous rich insights, none of these scholars centrally concern themselves with the effect of musical culture or the immediate situational context on perception.

Such criticisms of music theory and cognitive psychology are, of course, common among ethnomusicologists. As a discipline, ethnomusicology excels in constructing detailed studies of musical experience that show how perception, meaning and aesthetics are culturally specific. Research on areas as diverse as South Africa (Blacking 1967), Papua New Guinea (Feld 1982), and Native America (Vander 1988) implicitly or explicitly juxtaposes underlying systems of "native" musical perception with the norms of Western art music to display all musical perception as culturally based. Those ethnomusicologists specifically focused on temporal issues have shown how basic cultural assumptions about time and the organization of events affects rhythmic perception (Maceda 1986; Stone 1982, 1988; Merriam 1982). Their work does not merely reveal musical structures unknown to the Western European tradition (although it often does that); more fundamentally, it shows how the musical structures themselves are in fact artifacts of culturally specific systems of musical perception.

While such scholars are successful in pursuing this program, the systems of perception they posit are presented as descriptions of "the native's 
perspective," an idea that is problematic in a number of ways. The difficulty is not merely that all ethnography after Claude Lévi-Strauss's Tristes Tropiques (1973) and James Clifford's Predicament of Culture (1988) must account for the blurring of boundaries between self and other, the "native" and the "ethnographer." More fundamentally, the notion of native perspective leads the scholar toward a search for underlying cognitive machinery that produces experiences, thus obscuring the active role musicians and listeners play in constituting their perceptions; such an approach also makes invisible the complex differentiation of perception among the various participants in any given event. And while some cognitive scientists working in tandem with music theory or ethnomusicology have observed that a listening subject can perceive the same musical sound in several different ways, none of these scholars have taken the manipulation of perception as a central theme of research. ${ }^{2}$ My goal in this article is to show that the active organization of perception is a basic aspect of performance, and that discussions of musical structure can only be enriched by attention to the practice of perception.

\section{A Heavy Metal Drummer in Akron, Ohio}

The data I will present here must be understood as a first step toward an ethnography of the practice of perception among rock and metal musicians. As distinguished from rock, heavy metal refers to a range of highly dramatic musical genres that first appeared in the late 1960s and early 1970 s in Britain and the United States; metal emphasizes extremely distorted electric guitars, elaborate group arrangements, and individual virtuosity, and frequently depicts grim or aggressive emotions. While the study of popular music is a burgeoning area, little work has been done on the musical sound itself. Robert Walser's excellent book Running with the Devil (1993) is an exception to this general trend. But while Walser's book is unique and commendable for exploring musical sound in metal, Walser treats that music as a cultural object that has direct rhetorical and emotional effect on the listener. Analyzing transcriptions in the manner of a musicologist approaching a piece by Bach or Beethoven, Walser does not account for the fact that musicians can and do organize experiences of musical sound in a wide variety of ways. Thus, the various and complex practices of musical perception among heavy metal musicians are left unexamined.

Like most humanistic ethnomusicologists, my goal on entering the field was to share as much as I could of my informants' experiences of the music. I began my research in northeast Ohio in November 1992, and within a few months I had selected four distinct musical communities in which to work. One of these communities was the "underground" metal scene in the met- 
ropolitan Akron area. I began regularly interviewing musicians from two local metal bands-a small but respected death metal band named Sineater, and a progressive metal band called Winter's Bane that had just begun to leap from local to regional status and had signed a contract with an independent German label. ${ }^{3}$ I met Sineater's drummer, John Ziats, in early 1993; by August, we had had five interviews and a number of informal meetings. In our first interviews Ziats and I discussed the broadest contours of his musical life, including his early interest in metal, his vision of the local music scene, his history as a member of local bands, his development as a drummer, and his aims and purposes in music making. In our next interviews we explored how Ziats organized his experiences of the diverse elements of the performance event.

With these points established, we finally focused on interpreting his experiences of particular songs. Sineater had broken up a year before I got to Ohio, and all of its former members agreed that the last song they had worked on together, "The Final Silencing," was their finest effort; the song became the focus of study for a total of twenty hours of interviews among three of the six members of the band. In our fifth interview, we discussed the general form of the song and the first few sections. The sixth interview covered the third major section of the song (see Example 1), and it was in this interview that Ziats and I came to some unique understandings of musical perception in time.

After listening to a demo tape of the song and listening again to the part in question, Ziats began to share his experiences of this section of the song with me. My goal was to understand how he grasped the part and made it emerge in his experience: What was essential and what was unimportant about the part? What aspects were foundational and what were embellishments? Where did the interest and "action" lie in the part? How was the part organized in the ongoing form of his experience? As we began to interpret Ziats's experiences of his drum part, the common ethnomusicological ideas of additive and divisive time became indispensable to our inquiry. To understand Ziats's musical experiences, I will need to explore critically the ideas of additive and divisive time.

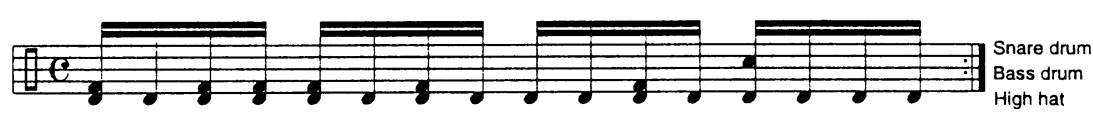

Example 1. Bridge drum part to "The Final Silencing" 


\section{A Theoretical Framework: Protension, Retention, and the Living Present}

The ideas of additive and divisive time are powerful but problematic concepts. Uncritically applied, they can lead the scholar to obscure the agent's active participation in perceptual experience. To guide inquiry into the temporal dimension of musical experience and clarify these ideas, a theoretical framework is needed; my approach emerges from the related, foundational insights of Henri Bergson (1916 [1889]), Edmund Husserl (1964 [1905]) and Alfred Schutz (1967 [1932]). ${ }^{4}$ The essential ideas of this school have been cogently explained in numerous locations (Ihde 1976:84103; Smith 1979; Stone 1988), but because the term phenomenology has been so consistently misunderstood, and because these ideas are so integral to my argument, I will review them here and apply them to the more familiar concepts of additive and divisive time.

The naive view of time perception is neatly captured in the image of the sweep second hand of the conventional wristwatch. Understood through the metaphor of that thin metal prong, the present is conceived of in daily language as an infinitely thin moment, endlessly gliding forward and turning future into past. (What time is it? It is one ten and five seconds, six seconds, seven seconds . . . ) Like all phenomenological research, the phenomenological inquiry into time perception begins with a rigorous examination of the lived experience of time, or, more accurately, the lived experiences of change, procession, and stability. When we set aside our common reflective prejudices about what time is and return to the lived experience, Husserl's basic insight becomes clear and manifest: the present is not some infinitely thin moment rushing ever forward, radically separate from the future and the past; on the contrary, we live in the thickness of a living present in which the as-yet-unfulfilled expectations of the near future and the just-past-certainties of the recent past form an undivided whole. Though constantly changing, the anticipated near future and lived recent past exist simultaneously and constitute the lived reality of present experience. 5

Some examples from language will illustrate the point. As I speak or listen, I am not merely aware of the words I say at the moment that I say them. As I hear or read one word, I am also simultaneously aware of the previous words spoken and have anticipations of the words to come. In Husserl's useful terminology, experiences of the recent past continuously experienced in the thickness of the living present are called retentions; anticipations of the near future extant in the thickness of the living present are called protentions. If we lived only in the infinitely thin present moment-that is, if we did not retain and protend-we could only be aware of the present word; complex sentence-level concepts would be an impossibility, because 
it is the experienced conjunction of the words across the moments that is responsible for the lived meaning of the sentences. ${ }^{6}$ Quite immediately and concretely, if the mere awareness of the individual words of the previous sentence-"if," "we," "lived" and so on-are taken by themselves and not retained, there is no possibility that the meaning of the sentence as a whole will emerge. It is only when each new word is conjoined with the retentions of the previous word and all are conjoined in the thickness of the lived and experienced present that the meaning of the whole sentence emerges.

It is important not to confuse retention with memory. To remember an earlier part of the sentence means to make a phenomenon that was once present (but is now absent) part of the living present once again; to retain an earlier part of the sentence means to continuously hold the earlier words in experience. Thus, to experience and understand a sentence, the reader does not merely glance back-with eye or memory-at the first words or clauses; on the contrary, understanding a sentence means to retain past experiences of past words and clauses, to let the their meaning lurk in retention and let their conjunction with the new, incoming words provide added sense and meaning. A momentary failure of retention will illustrate the difference between memory and retention in the clearest fashion. Reading a long sentence, I may become confused and have to actively remember or glance back at previous words or clauses. Here, I do not understand the sentence because I have failed to retain the first words in the thickness of my living present; I engage memory to bring those first words and clauses back into the living present in the hope that I may now retain them while I re-read the latter phrases and thus make sense of the sentence as a whole. Thus memory is being used to refresh retention, returning old experiences back into the protentional/retentional structure of the living present. Retention is an indivisible aspect of the living present; distinct from memory, retention is necessary if experience is to occur at all.

We can further this understanding by observing that experience does not merely have a protentional/retentional structure; the structure of the living present is organized and can be managed along a number of parameters. In all experience, protentions and retentions may be differentially foregrounded or backgrounded, and the span of the living present may be expanded or contracted. ${ }^{7}$ To the issue of the span of the living present: reading Bourdieu after an exhausting day, I may have difficulty keeping all the parts of his long sentences present in retention; in such a case, we might say that the concrete dimensions of my living present are cramped, and I am only able to focus on a narrow temporal width. Alternatively, while in a state of calm attentiveness, I may be able to hold all of the nested clauses of Bourdieu's aggressively complex sentences in retention, conjoining them with the incoming clauses and thus broadening the temporal width of the living present. 
Don Ihde speaks to the issue of foregrounding or backgrounding experiences in retention or protention (1976): while anxiously waiting for a telephone call, I may focus attention on the leading edge of the living present, protending and anticipating the sound of the bell and almost ignoring the retentions of all sounds that pass beyond the now-point. Alternatively, listening calmly but intently to a piece of music, I may languorously enjoy each note, allowing their continuity and retention to remain in experience and foregrounding the retained moments and their continuity.

We can both better understand these ideas and prepare for our return to the interpretation of Ziats's experiences by applying them to the concepts, so familiar to the ethnomusicologist, of additive and divisive time. It is a commonplace of past ethnomusicological discourse to hold that time in West African music is perceived in an additive fashion while time in European music is perceived in a divisive fashion. ${ }^{8}$ Not even addressing the post-modern recognition of blurred cultural boundaries, it is necessary to examine these ideas closely and see exactly how they might describe lived experience. At first the notions seem quite clear: additive music is music that is constituted by adding small temporal units together. For example, one way in which the so-called standard pattern of West African music can be understood is as a musical idea composed by adding together-or, more precisely, placing in series-five small groups of beats: one, two; one, two; one, two, three; one, two; one, two, three. Divisive music is constituted by taking a larger span of time and dividing it into equal units; common four/four time in Western art music is understood as a unit of time (one bar) divided into four quarter notes, four equal divisions.

Beyond the common but obviously flawed conflation of divisive versus additive time with even and odd meters, even before employing Husserl's concept of the living present it is apparent that the same piece of music could be perceived in an additive or divisive manner. A listener may hear the same beats in a piece of music either as composed of a series of small units added together or as a larger temporal unit divided into parts. (For example, in Drum Gabu, David Locke urges the reader to explore both additive and divisive approaches in hearing the rhythms of Ewe drum ensembles (1987, 17-19).) Nothing inherent in the sound dictates that we hear it as beats added up or a unit of time divided, and the distinction between the two is a distinction in the listener's culturally based organization of their experience, not in the vibrations of the the air itself. (In fact, there is more complexity here, but I will return to this point below.) Phenomenologists refer to perception as a process of constitution; unlike construction (the whole-cloth creation of ideas from imagination), in constitution we actively engage with the world and make it emerge in experience. In the language of phenomenology we may say that we are free to constitute the percep- 
tion of a series of beats in an additive or divisive fashion. Addition and division are two of many ways in which a listener may organize protentions and retentions of musical experience in the thickness of the living present. In the following discussion I will ground the notions of additive and divisive time in the rigorous analysis of lived experience. This exploration will provide us with the intellectual tools needed to understand the heavy metal data and enable us to draw further conclusions about the role of agency in perception and the differentiation of perceptual practices within a culture.

What is the structure of the living present when we perceive time in a divisive manner? Because of the complexity of the issue, let us take an extremely simple case: the experience of four beats heard as a series of quarter notes in four/four time. At the moment that the first beat is sounded, if the listener is to hear it as a division of a larger temporal unit, he or she must concretely protend the other beats of the bar; that is, the listener must experience, in the temporal "space" of the near future, three more beats while he or she is hearing the present beat in the now-point. (Further, the listener is likely to protend future units of four linked beats, but this brings us to the topic of larger levels of temporal organization, which is beyond the present moment in the argument.) When the second beat is sounded, the listener must conjoin this new beat with the retention of the first beat and the protention of the two upcoming beats. Likewise, the listener must conjoin the third beat with the retention of the first two and the protention of the fourth; similarly, the listener will conjoin the fourth beat to the retentions of the first three and actively disjoin these beats from the beats of the new bar emerging now in immediate protention. It is this dynamic and ongoing structure of retention and protention that constitutes the experiences of hearing four beats as divisions of a larger temporal unit. We can observe more broadly that through the period attention is constantly focused on the level of the bar as it moves from pure protention to pure retention and that, as each beat emerges in the focal point of the "now," it is experienced as a figure against the ground of those moving protentions and retentions. In fact, it is this figure/ground relationship between present beat and the protended and retained beats that constitutes the experience of any beat as a quarter note and as a division of the bar.

Now, what is the structure of the living present when we perceive time in an additive manner? Let us again take a simple case: a pattern of two beats plus three beats. ${ }^{9}$ As above, when the first beat is sounded, we protend the upcoming beat as part of the same temporal unit; similarly, when the second beat is sounded it is conjoined to the retention of the first. When the third beat emerges, it appears against the ground of the protended fourth and fifth beats; similarly, the fourth beat emerges against the ground of the retained third beat and the protended fifth; when the fifth beat finally 
emerges, it is conjoined with the retentions of the third and fourth beats. We must additionally observe here that, while the first two beats are sounded, the third, fourth and fifth are still protended, and, similarly, as the third, fourth and fifth beats are sounded, the first and second of the first repetition of the pattern are also protended.

The critical point here is that beats one and two are tightly conjoined as they pass from protention through to retention, just as beats three, four and five are tightly conjoined as they proceed through the living present. Of course the two small temporal sub-units are also conjoined to form the pattern, but their conjunction is of a higher order-a conjunction of units of beats rather than a conjunction of beats themselves.

With this in place, we are finally in a position to come to an explicit and concrete description of the difference between additive and divisive time. Further, we can begin to see the first glimmerings of the connection between these specific issues in temporal perception and the broader argument about perception as social practice. Additive versus divisive time refers to methods of organizing experiences in the processual, temporal thickness of the living present. In divisive time, the large temporal level of the bar is the ongoing background against which each beat emerges; in additive time, each beat emerges against the background of smaller two or three beat units, which themselves are conjoined to form larger units. ${ }^{10}$ The difference between the two methods of constituting perception is that the listener engaged in divisive time places individual beats against the background of the bar as a whole, while the listener engaged in additive time places the individual beats against the background of small sub-units, which in turn are placed within the context of the pattern as a whole.

The critical distinction lies in the relationship of the immediate beat to larger levels of protention and retention. Both the additive and divisive processes of constituting perception requires the listener to experience large units at the level of the bar-as-a-whole or the pattern-as-a-whole. The two differ with respect to which level of protention and retention the immediate beats are related to most intensely. In the divisive process, each beat emerges intensely locked in a figure/ground relationship with the retained and protended notes of that bar. In our example, the third beat is tightly conjoined with the protention of the fourth beat and the retention of the first two beats; it is merely a division of the larger unit and is illuminated by its relationship to the numerous protentions and retentions of the larger temporal whole. In the additive processes, however, the beat emerges more tightly conjoined with the others of its small sub-unit, and the pattern as a whole is more deeply backgrounded. In our example, beat four is tightly conjoined with the retention of beat three and the protention of beat five; of course, beats one and two of the current iteration of the pattern 
are still retained and beats one and two of the upcoming iteration of the pattern are still protended, but they are protended less intensely. Further, it is each sub-unit as a whole, and not the individual beats taken by themselves, that constitute the pattern. Thus, for divisive processes, the primary and defining relationship is between the immediate beat and the protentions and retentions on the level of the bar-as-a-whole; for additive processes, the primary and defining relationship is between the immediate beat and the protentions and retentions on the smaller level of the sub-unit, which in turn are secondarily related to protentions and retentions on the level of the pattern as a whole. ${ }^{11}$

The reader will of course have noted that in this section I have shifted from speaking of additive or divisive time to additive or divisive processes of perception. It should be apparent that the issue here is the listener's method of grasping the world and making it emerge in experience. My goal in the rest of this article is to suggest that the issues at stake in ethnomusicological studies of perception are not of underlying cultural schemes that produce perception but rather practices of perception-practices grounded in the participants' social pasts and situational goals, differential across the participants within the event and open to the possibility of creative manipulation or failed execution. Such practices need not be either guided by explicit thoughts or reflexively understood, but there is no reason that they may not be. In either case, they are at least partially the outcome of the musical participant's agency; to borrow a phrase from Giddens, this is the case because, engaged in practice, the participants "could have acted otherwise" (1979:56).

\section{Initial Exploration of Ziats's Musical Experience: An Interpretive Dialogue}

With this theoretical orientation in mind, we can turn to my sixth interview with Ziats and begin to garner some important insights about his musical experience and the practice of perception. Earlier interviews had revealed that the snare drum (usually accenting beats two and four in rock musics) and the bass drum (usually falling on beats one and three) were often linked, and it took little time to establish that the snare and bass drum parts formed one unit in Ziats's experience; ${ }^{12}$ similarly, the flow of sixteenths played on the high hat or "sock cymbals" formed a separate but related unit. Attempting to understand the relative importance and functions of the various units, I then asked Ziats which part (snare and bass, or high hats) he would play if he was only allowed to play one; Ziats said that independent of which drum he would use, he would play the flow of sixteenth notes because it formed the foundation of the drum part. A rock musician myself, I had always understood the accents on two and four as 
central to the music. To my surprise, additional conversation strongly confirmed that Ziats heard the flow of sixteenth notes as the basis of the part. To him, the snare and bass drums were merely accents in the flow of sixteenths.

Ziats was not at all surprised that I heard two and four as foundational to the part. The audience hears the snare first, said Ziats; the other band members tap out the quarter notes, but drummers build up their parts from small units. Ziats then explained how the song was put together in rehearsal. Guitarist and main song writer Dann Saladin composed a series of sustained power chords for this section. ${ }^{13}$ In rehearsal Ziats had to compose a drum part to go along with Saladin's guitar part and, in his aural imagination, conjured a flow of sixteenth notes, much in the style of Queensrÿche drummer Scott Rockenfield; immediately after, he decided to add the snare and bass parts as a layer on top of the high hat's foundation. Most importantly, this method of composition-building up parts by layering larger temporal units above smaller ones-paralleled the manner in which he structured his listening in performance. Ziats explained that while the audience usually focuses on two and four and the guitar players tap out the flow of quarter notes with their feet, Ziats himself would focus on the sixteenth notes to keep the time both metronomic and flowing. If a player just "listened to the air" (that is, the huge silences) between two and four, he or she could easily get lost, said Ziats; focusing on the sound of the flow of sixteenth notes and the feelings of his arms articulating those parts, he said, helps him perform evenly and with authority. ${ }^{14}$

Engaging Ziats with ideas from my training, I explained the common ethnomusicological (non-phenomenological) notions of additive and divisive time perception, and I asked Ziats if he felt that his focus on the sixteenth notes was an example of the use of additive time. Ziats agreed heartily, and to hammer home the point, he described a part he had recently composed for a song his current band was writing. The part was formed by adding together three smaller rhythmic fragments-two seven stroke rolls shared between the bass and snare and pattern of five short pulses. Ziats was emphatic that he composed the part using an additive approach. Had the interview ended here, the simple conclusion would be that Ziats's scheme of perception followed the additive pattern. Given more supportive data, the conclusions one would draw would fit into the general form of traditional ethnomusicological inquiry: the people from $\mathrm{X}$ culture perceive musical sound in Y manner. Further conversation, however, revealed the problem of such a interpretation.

Ziats and I applied the notions of additive and divisive time to other drum parts, and we began exploring this part in more detail. Ziats's drum kit was unavailable during our interview, but he did have a pair of drum sticks with him; at one point I asked him to play his drum part on the sur- 
faces available in the room. Like the metal (and rock) guitar players I had interviewed, Ziats tapped out the quarter notes with his foot. After I pointed this out to him, Ziats explained that in an abstract sense, the quarter notes were the most basic and foundational level of the time; the bars were composed by adding quarters together and the sixteenth notes composed by dividing the quarters into four parts. I began to suspect that the conclusion that Ziats perceived the part in an additive fashion might be premature, and I wondered if the idea that one temporal level was always perceived as a rhythmic foundation might be an abstraction from the concrete practice of playing and perceiving music. In fact the more important question was not which level was more foundational but which level stood in the foreground of the living experience of musical performance, when, and for what reason. Examining different scenarios and types of events, Ziats and I concluded that if he wanted to get into the smooth grooving feel of the part (the usual case) he would focus on the flow of sixteenth notes as he first indicated; however, if the band was not tightly coordinated with the drums or his time was especially poor, he would focus on the quarter notes (that is, the first of every four sixteenth notes on the high hat); if the band was well coordinated and he wanted to connect with the audience, he could focus on the beats that they heard most strongly-two and four.

Before turning to broader points in the discussion, it is important to note that heavy metal (like many rock-based musical genres) is rich in rhythmic complexity, and the apparent simplicity of this example should not lead the reader to misunderstand the sophistication of heavy metal drummers. Changes in tempo and groove, complex fills and all manner of compositional and performance techniques give metal its diversity and power. By exploring the creative organization of attention in this one simplified example, my goal is to display musical perception as an active process. The organization of awareness in the perception of more complex parts, the shifting of attention to different instruments in the ensemble, the musicians' attention to non-aural aspects of the performance event and the partial sharing of experience between musicians and audience members is the focus of several chapters of my dissertation (1995). While this paper has focused on the active organization of experience in the narrow confines of this one simple musical example, the possibilities of creative social perception in the full range of elaborated musical structures and situated contexts is immense.

\section{Interpretation of the Musical Experiences I: The Concept of Multi-functionality}

At this point in the interview, it became apparent to me that focusing attention on different temporal levels in musical perception involved the 
same principle of multi-functionality that Prague school semiotician Roman Jakobson had suggested for language (1960), so I explained the idea to Ziats. Jakobson argued that all verbal interactions involve six distinct dimensions, each with its own function; all six dimensions and functions occur at once, but in different interactions some functions may be emphasized more than others. For example, two of the dimensions are channel and reference: channel refers to the physical media by which the communication is established, and reference refers to the denotations and meanings of the words. Both channel and reference are a part of every communication, but the context and the interlocutor's goals determine which dimensions will be foregrounded and which will be backgrounded. Talking on the phone when the line is clear, for example, I may forget about the complex technology that enables our conversation and focus on the meanings of my interlocutor's words. Here, reference is foregrounded, but it must be understood that channel is present as part of the background. By the mere act of talking, the speaker implicitly confirms the fact that he or she assumes the channel is still operative and the other is listening; otherwise, he or she would not be conversing but merely talking to him- or herself. Alternately, if static obscured the line, the precise meanings of the other's words would become of secondary importance. As both speakers shouted "Hello? Hello?" the dimension of channel would be quickly shifted to the foreground. In its broadest sense, to say a sphere of experience is multi-functional is to say that it has numerous simultaneous dimensions, each of which is always operative and each of which may take the foreground of attention at any moment.

Speaking about rock and metal in general as well as this song specifically, I suggested to Ziats that the focusing of attention on different temporal levels in music perception was multi-functional. It was clear from the interview that focusing on any one level had certain consequences and could be used to serve a particular purpose in the performance event. Thus, the sixteenth notes flow by in a swift and uninterrupted fashion, and by focusing on these the drummer can enter into the flowing groove of the music. The quarter notes exist as a mean between the swiftly flowing sixteenth notes and the widely spaced two and four; they are also the level that the other band members tend to tap out. By focusing on these, the drummer may coordinate more tightly with the other band members. Finally, because the heavy accents on two and four are what draw the audience's attention most intensely, a focus on this level is useful in helping the drummer project his part out to the crowd and draw them into the music. Ziats explained that, if on a given night his tempo was not consistent or the band was not well coordinated, he would focus on the quarters. If the basic coordinations were not a problem, as was usually the case, he would let his attention drift to the level of the flowing sixteenth notes 
and let the groove roll along smoothly. Alternatively, he could focus on two and four to connect more directly with the crowd.

But the various temporal levels are not merely functional; they are multifunctional in Jakobson's sense. That is, all of the levels occur simultaneously, as do all the functions. As Ziats attends to the rolling flow of sixteenth notes, he is also simultaneously playing the quarters (as articulated by the accented first note of every four on the high hat) and the snare and bass on two and four; likewise, he is simultaneously coordinating his part with those of the other band members and the gestures and body movements of the audience. All of those functions and levels occur, and the foregrounding of any one level (and subsequent backgrounding of the other two levels) is achieved to serve Ziats's needs in that particular performance event. Discussing the idea of multi-functionality and its application to the issue of temporal focus in performing this part, Ziats agreed that Jakobson's notion did indeed describe his musical experiences and that he would shift his attention from flowing sixteenths to solidly spaced quarters depending on his needs in the event.

\section{Interpretation of the the Musical Experiences II: Protention and Retention}

We can use this data to understand musical perception as a kind of practice; indeed, the outlines of that argument should be clear to the reader at this stage of the analysis. But the phrase "the focusing of attention at different temporal levels" is broadly stated, prone to misinterpretation, and reveals little about the musician's experiences and the manner by which he or she constitutes them. The notions of additive and divisive time provide some help, but, as I have shown above, these ideas are still much less explicit and revealing than one would like. How, for example, does a listener constitute additive or divisive perception in particular situations and what are the concrete differences in experience between the two? To explicitly and systematically understand the temporal dimension of musical experience, we must examine the anticipation, emergence and retention, the continuity and discontinuity, the foregrounding and backgrounding and the dynamic play of presence and absence in the experiencing of musical sound. In fact, the "focusing of attention at different temporal levels" refers to processes of organizing musical sound in the living present. My goal here is to use the intellectual tools from phenomenology to provide an explicit description of the experience of this processual organization. Unlike the above discussion of Ziats's experience, these descriptions have not emerged in the fieldwork dialogue and therefore must be seen as tentative hypotheses in the phenomenological ethnography of heavy metal and rock. 
The differences between "focusing on the sixteenths" and "focusing on the quarters" most closely parallels the differences between additive and divisive time explored above and will thus serve as a starting place. Let us begin with the experience of the sound of the high hat. Following my earlier discussion, it is clear that "to focus on the level of the quarter notes" means to hold all the quarter notes intently in experience as they process through the narrow center of the living present. Thus, on beat one, the high hat stroke in the now-point is highlighted or foregrounded. Simultaneously, the other fifteen sixteenth notes of this bar are protended as well, but the sixteenth notes falling on the downbeats are foregrounded, while the other twelve (the notes falling on the "e," "and," and "ah" of beats one, two, three and four) are grasped more lightly and are held in the defining background. ${ }^{15}$ The same foregrounding and backgrounding relationships take place as the notes are protended, performed and then retained in the trailing thickness of the living present. On the "and" of three, for example, the high hat strokes on the first three downbeats are foregrounded in retention, while the upcoming high hat stroke on the downbeat of four is intensely protended. Likewise, the sixteenth note divisions of the first two beats and the " $e$ " of beat three are retained, while the "ah" of beat three and the three off-beat sixteenths of bar four are protended. However, these notes are grasped less intensely and are thus less vividly central in experience; they act as a defining temporal background to the foregrounded retention and protentions of downbeats in the same way that the irregular white center acts as a defining spacial background to the two silhouetteshaped black patches in the famous Rubin's Goblet drawing.

In sum, the foregrounding of the high hat strokes on the downbeats as they process from protention to retention is the concrete, experienced reality that the term "focusing on the quarter notes" imprecisely describes. The presence, in the background of experience, of the three notes of equal duration dividing up the silence gives the part its sixteenth-note "feel."

In fact, there is even greater complexity and richness here that these descriptions elide. The previous discussion did not examine the relative foregrounding and backgrounding among the notes on the downbeats. Such factors as the note's distance from the now-point, its presence in protention or retention, and its status as a strong beat or weak beat (understood from the subject's perspective, of course) all would play a role in determining the intensity with which it is grasped compared to the other notes falling on the downbeats. While there is no doubt that all experiences of musical sound occur in the thickness of the participant's living present, and while it is clear that the focusing on different levels of time is achieved by organizing sound in the living present, the richness of lived experience always transcends our descriptions of them; further, descriptions based in theo- 
retical generalizations and not returned to the fieldwork dialogue are most subject to error. Therefore, these descriptions must be understood as hypotheses to be explored in future fieldwork. This does not mean that these descriptions are mere speculation, and I hope that they will guide the way to more nuanced conversations between myself and Ziats, as well as between other researchers and musicians.

Having examined the organization of the living present necessary for "focusing on the quarters," it will be easier to explicate the organization necessary for "focusing on the sixteenths." First of all, it is not clear from the context of the interview whether the phrase "focusing on the sixteenth notes" was meant as "focusing on the sixteenth notes as heard in groups of four" or "focusing on the ongoing flow of sixteenths;" I will thus handle each case separately. The former case is not very different from my initial examination of additive time. Focusing on the sixteenth notes as groups of four, the drummer will foreground the present note and tightly conjoin it with the other notes in their emerging four-note unit. Thus, for example, as the second sixteenth of beat three emerges, it is tightly conjoined with the retained sixteenth note on the downbeat of three, as well as the protentions of the sixteenth notes on the "and" and the "ah" of three. Just as the sounds in a word are not merely heard as separate entities but grasped together to form a synthetic whole, these sounds will be grasped together as they process from protention, through the now-point and into retention. These four-note units are then conjoined to form the bars at a higher level; just as a sentence is experienced as groups of phrases and not merely serial strings of sound, the bar as a whole is experienced as groups of fournote units and not merely strings of individual notes by themselves.

Given the context of the interview it seems that the second case, that of "focusing on the sixteenths as an ongoing flow," is more likely what Ziats intended when he referred to "focusing on the sixteenths." This situation would be marked by a less intense contrast of foreground and background than was present in the earlier cases. Rather than strongly foregrounding the notes that fall on the downbeats and strongly backgrounding the notes that fall on the off beats as they process through the living present (the case of focusing on the quarters), the listener focusing on the sixteenth notes grasps the notes more evenly, flattening out the difference of intensity between the vivid foreground and the vague background. The result is the experience of an ongoing flow of sixteenth notes continuously processing from protention to retention rather than of a series of quarter notes emerging against the background of a sixteenth note "feel." When focusing on the flow of sixteenths, the present note is foregrounded against a ground of ever-approaching protentions and ever-receding retentions.

It should be clear that a smooth continuum exists between the two 
cases of focusing on the sixteenths. Thus, the more tightly conjoined the adjacent groups of four within experience, the more they are heard as a flow of four note units emerging across the span of the section; the more loosely the groups of sixteenth notes are conjoined, the more the high hat part sounds like an endless string of sixteenth notes. It should also be clear that both situations are sharply distinct from a focus on the quarters, which present the notes on the downbeats as sharply foregrounded against a background of sixteenth note divisions; the distinction between "focusing on the quarters" and "focusing on the sixteenths" is precisely the same as the elaborated phenomenological descriptions of the distinction between additive and divisive time.

While all of this takes us a long way toward a more explicit understanding of the concrete differences between focusing on the quarters and focusing on the sixteenths, we must recall that we have neglected the place of the snare and bass drum parts in the experience; returning it to the discussion will not be difficult. It was clear and explicit from this and previous interviews that Ziats heard the flow of sixteenth notes as one coherent unit and the bass and snare drum parts as another coherent unit. ${ }^{16}$ Like a part hocketted between a soprano and a bass or a simple two-note melody, the snare and bass parts are tightly linked with one another and form a unit sharply distinct from the flow of sixteenth notes on the high hat. ${ }^{17} \mathrm{With}$ each maintaining its own internal foreground and background relationships in experience, the two parts also fall into a foreground/ background relationship with one another: when "focusing on the quarters" or "focusing on the sixteenths" the snare and high hat part form an ongoing background to the foregrounded high hat part. It is important to recall here that backgrounded experiences are not absent from experience; on the contrary, they are present in a vague form and often are a key part of the lived experience as a whole. Just as a quiet, inner melody in a complex, multi-part piece of counterpoint informs and colors the more obvious and foregrounded upper voice, so do the ongoing snare and bass part, taken as a unit, become a defining background for the foregrounded high hat part.

And just as a listener may shift attention between the melodic lines in a piece of counterpoint, so may Ziats shift attention from the hats back to the snare and bass. Such a spatial and timbral adjustment of attention is precisely what is meant by "shifting focus" from "the level of the sixteenths" or "the level of the quarters" to "the level of two and four." This ability is not obscure, and a variety of such selective attention is well known in perception psychology as the "cocktail party effect." Just as an individual holding a conversation in a loud party may foreground her or his interlocutor's words and background the general din of the affair, or let the interlocutor's words slip into the background to eavesdrop on another 
speaker's words, Ziats may foreground either the snare and bass or the high hats, while allowing the other to slip into the defining background of his experience. Because of the accents in the snare and bass part (and because the norm in rock and metal is for the snare to heavily accent two and four), a spacial and timbral shift of attention to the snare and bass means that the protended and retained notes on two and four become the most foregrounded; thus, "the level of two and four" becomes the de facto focus of attention.

\section{Conclusions and Future Directions: The Organization of the Living Present as a Practice of Perception}

The primary purpose of phenomenological ethnography in ethnomusicology is to describe the musical experiences of others. Musical sound is not merely present in the world; it is an artifact of an individual's grasping of the world in perception. People with different social histories and cultures grasp the world, and thus experience it, in very different ways. By reading an ethnography that describes how those with different social histories grasp their music in perception, a person can come to understand a music that might otherwise be incomprehensible. As cross-cultural translation, phenomenological ethnography in ethnomusicology is not much different from early ethnomusicological work that sought, as I suggested above, to garner "the native perspective."

However, my goal in this paper has not been merely descriptive. A basic tenet of the phenomenology of perception is that perception is actively and socially achieved by the participants. Studies that focus on musical sound alone carry with them the implicit assumption that perception is universal and that what varies from culture to culture are the types of artifacts produced; phenomenological approaches assume that both the music perceived and the act of perception are specific to each musical culture. ${ }^{18}$ While structuralist approaches often recognize that perception varies with social history, such approaches seek to unearth unconscious systems that generate experiences for the musical participants; phenomenological approaches, however, assume that there are at least some aspects of the constitution of perception that are accessible to the participants and over which those participants have some level of control. Further, as a kind of modernism, structuralist approaches assume that there is one underlying scheme of perception in each culture and implicitly or explicitly take as their study object an ethnomusicological variation of Chomsky's ideal speaker/hearer in the homogeneous speech community; phenomenological approaches take the concrete individuals and diversity of their experiences as a study object, and one result of this is to discover complex and reciprocal relationships in the practices of perception of the participants in each event. 
In sum, phenomenology takes perception to be a kind of practice or action. As such, the broad generalizations about practice developed by such theorists as Bourdieu and Giddens also apply to the act of perceiving. Thus, as practice, each act of perception is dependant on the individual's social experiences and the broader social history that led up to them; such a social history influences but does not determine perception, and each act of perception depends on the individual's active and agentive engagement with the world. To the musician who has spent long hours learning to hear complex chord changes or subtle nuances in pitch or tempo, the idea that one's perception is grounded in one's social history but at the same time actively achieved should be easy to accept. Further, as practice, perception is oriented toward the agent's goals and intentions in the performance situation, and yet such acts have a range of consequences some of which often run counter to the actor's intent. For example, different performers see different members of the rhythm section as the rhythmic foundation and subtle difference of tempo are crucial. On a small scale, the present vision of intentions and consequences should be comprehensible to the jazz soloist who has studiously followed the tempo of the drummer throughout a performance, only to find that the rest of the band was following the bass's tempo. My goal in presenting this detailed description of the organization of the living present is to show the rich data and insights that emerge when we treat perception as practice.

First, it should be clear from this discussion that perception is never simply a mirror of the world, though neither is perception mere fantasy. "Focusing on the sixteenths," "focusing on the quarters," "focusing on two and four" - the discussion of the organization of the living perception showed that there are numerous ways in which Ziats's drum part may be grasped in perception; in fact, the part is open to an almost endless variety of possible combinations of foregrounding and backgrounding, conjoining and disjoining for a listener willing to experiment with perception. Second, and perhaps more important, the data show that it is simple and comprehensible acts (foregrounding and backgrounding, conjoining and disjoining) that determine how the part will be perceived. Choosing among an open-ended range of possibilities of perception, John Ziats is no cultural dupe whose experience of the world is generated and determined by unconscious structures; on the contrary, he is an agent constituting perception. Further, the structure of his experience is manifest in the event itself, and the practices by which he constitutes those experiences are accessible to him, both in private reflection and in the dialogue of the ethnographic interview. Third, and related, the selection between different ways of organizing the living present is not arbitrary or capricious but rather geared toward the participant's musical goals in the performance event. Further, by "focusing on the sixteenths," a phrase we now can use to mean an ex- 
plicated method of organizing musical sound in the living present, Ziats can enter into the groove of the music. By "focusing on the quarters" Ziats can correct any basic tempo problems that might occur, and "focusing on two and four" can be used to draw the audience into the performance. Fourth, perception is not something that is achieved identically by all the participants in an event. For example, almost all of the heavy metal and commercial hard rock guitarists I spoke with said that the drummer was the player most responsible for the tune's overall groove; as a result, the guitarists explained, they mainly focus on the level of the quarter notes and would follow the drummer's tempo almost anywhere it led. The audience members have no responsibility to stay synchronized, and they generally grasped as most central the loudest and most obvious part of the music-the snare accents on two and four. As such, Ziats's perceptual practices do not merely serve individual ends but are oriented toward others in the event. Finally, displaying precisely how these particular perceptual practices are tied to the long term events in Ziats's musical life, as well as the history of heavy metal and American music more generally, is a crucial project best accomplished by cross-cultural comparison and a comprehensive social history of musical perception; such a study is clearly beyond the scope of this article.

Having viewed Ziats's perception as fulfilling narrow musical goals in the context of the event, we have almost reached the end of the discussion. But it must be remembered that all narrow situational goals-musical or otherwise-are connected to the actor's larger plans and projects, and that these have consequences that always exceed the actor's intentions. Thus, the narrow musical goal of presenting a tightly coordinated and aggressively grooving band may seem unremarkable and prosaic, but this is not the case when placed within the broader context of the purposes and consequences of heavy metal more generally. As such, perceptual practices should not merely be of interest to those who study musical sound but also to those who study music's role in society, history, and politics writ large. It is only when we understand even the largest-scale social and musical movements as actively constituted by the social actions of individuals that we can view society and history as meaningful and living experience.

\section{Notes}

1. For a fuller exploration of practice theory and its applicability to the ethnomusicology of perception, see Berger 1995, especially chapter one.

2. Bringing cognitive science approaches to music theory, Fred Lerdahl and Ray Jackendoff [1983], for example, suggest that the musical score may imply more than one musical structure and posit "preference rules" to account for the possibility of differing interpretations. Brower (1993:24) voices similar observations. Bringing cognitive science approaches to eth- 
nomusicology, Ulrich Wegner (1993) also notes that musical structure can be construed in varying ways.

3. The term "underground" refers to the varieties of heavy metal that exist largely outside or on the margins of the mainstream music industry and receive little commercial airplay. Death metal is a subgenre of underground metal that began in the mid-eighties and is primarily characterized by deep, growly, unpitched vocals. When used to modify the name of a variety of rock or metal, the adjective "progressive" is used to indicate that the band employs complex musical structures. Sineater could be described as a kind of progressive death metal, employing growly unpitched vocals and highly elaborated song structures; Winter's Bane was closer to the commercial end of the underground metal scene, but the band's songs were sufficient in length and complexity to make their music "progressive metal."

4. In many ways Jacques Derrida's early critiques of Husserl's ideas on time (1973, especially pages 60-70) share common features with Husserl's thought, and an interested reader might find his work relevant to this discussion as well.

5. Christopher Hasty has recently applied this basic Husserlian insight to show that even the most apparently discontinuous contemporary Western art music is in fact experienced in the thickness of the living present (1986:61-62). Brower has also connected similar observations from William James with music research (1993:22).

6. The terms "conjunction" and "disjunction" were most fruitfully applied to the relationships between and within experience by William James (1967 [1912], especially pages 44-52). By "conjunction" James meant the lived connections of experiences across phenomenal space and time while "disjunction" was used to refer to the lived spearation of experiences. While Husserl never uses precisely those terms, we can understand the ongoing continuity of protention and retention in the living present as a kind of temporal conjunction. On the compatibility of Husserl's phenomenology and James' radical empiricism, see James Edie (1987).

7. I am using the terms foreground and background here in an abstract, general, and. descriptive sense. When an entity in experience is foregrounded, it is experienced with greater emphasis, detail, and clarity; entities backgrounded in experience are not "less experienced" by the subject. They are, however, less emphasized, and are present to the subject with less detail and clarity. I am using these two words as technical terms to describe the lived organization of experience, not as visual metaphors for sound experiences. I intend the same abstract, descriptive organizational approach with the use of the term "temporal level," which I develop below.

8. While some writers maintain this idea (e.g. Small 1987:269-273), recent ethnomusicological work on Africa has surpassed the simplistic equation of additive time with West African music and divisive time with Western European music (see Kauffman 1980; Stone 1985).

9. It is important here to realize that odd versus even meters must not be conflated with additive versus divisive time. One can perceive a pattern of four repeating beats in either an additive or a divisive manner. I use the example of a simple pattern of two plus three because such patterns are commonly associated with additive time, but no necessary connection exists.

10. Considering musical experience from a very different perspective, auditory perception scholars have also explored the grouping of sounds across time into coherent rhythmic units and the existence of multiple levels of temporality. A good overview of this literature can be found in Handel 1989:383-419.

11. As always in phenomenological research, my goal is to set aside previous philosophical presuppositions, return to the living experience itself, and describe that experience as effectively as possible. My aim here is not to dictate the organization of experience in additive or divisive perception but to describe these methods by which listeners organize their perceptions. While the reader may feel that my descriptions are more or less accurate, it should be clear that this is in no way intended as a prescriptive account, nor is this section ethnographic. 
12. In fact, the snare and bass parts in the section we were discussing are slightly unusual for this genre. In rock and metal, the norm is for the snare drum to strongly accent two and four. This fact was supported by interviews with other drummers, and throughout our interviews Ziats and I regularly conflated the temporal level of two and four with snare parts in general. As such, these remarks are relevant to both Ziats's experiences as a whole and those of most metalheads.

13. In many forms of American popular music, the term "power chord" is regularly used to refer to a chord composed of the root, the perfect fifth and the octave. Power chords are sometimes composed of the root, the fourth and the octave; on occasion the power "chord" is limited to the interval of the fourth or fifth. These forms are common to most forms of rock and metal.

14. In the contemporary discipline, a body of writing has emerged examining the subtle, positive discrepancies between the musicians' performances and the metronomically precise underlying pulse (most recently, Keil 1995; Prögler 1995; Alén 1995). These authors view playing "ahead" or "behind" the beat, and myriad other "discrepancies," as the basis for the experience of "grove" or "swing" in music. This important work reveals new dimensions of rhythmic organization, and Ingrid Monson's recent comments suggest that performers actively manipulate this dimension of musicial structure in performance (1995:87-99). As a dimension of structure, groove, swing, and participatory discrepancies are all subject to perception, and future research might focus on the active organization of perception at the micro-level and the effect of perception on the groove or swing of a performance.

15. By the syllable " $e$ " I mean to indicate the first sixteenth note after the downbeat; by "and" I mean to indicate the sixteenth note falling in the middle of the beat, and by the syllable "ah" I mean to indicate the last sixteenth note of the beat. This syllable usage is common among drummers in many Western traditions, including rock and metal.

16. Approaching musical experience using different methods, auditory perception scholars have also noted similar effects. The grouping together of the snare and bass in experience would be referred to as "streaming"; the separation of the streamed together snare and the bass sounds from the high hat sound would be referred to as "stream segregation" (cf. Bregman and Pinker 1978; Handel 1989, 185-218).

17. Ziats said in our interviews that, while the bass and snare parts are almost always taken together to form a coherent unit, this relationship can be understood in a number of other ways (for example, as a rhythmic call and response). Walser has also observed what he calls a dialogic interaction between bass ans snare drum parts (personal communication, 1995).

18. The standard example of this insight from the field of phonetics revolves around the phonemes " $r$ " and "l." It has been repeatedly observed that speakers whose native language does not contain these phonemes do not merely have a difficulty producing the English sounds " $r$ " and "l;" they are also frequently unable to perceive them as well. Using rather different approaches from phenomenology, phonetics has also arrived at the insight that the act of perception is deeply dependant on learning.

\section{References}

Alén, Olavo. 1995. "Rhythm as Duration of Sounds in Tumba Francesa." Etbnomusicology 39:55-72.

Berger, Harris M. 1995. "Perception in the Moral Continuum of History: An Ethnography of Metal, Rock and Jazz in Northeast Ohio.” Ph.D. diss., Indiana University.

Bergson, Henri. 1916 [1889]. Time and Free Will: An Essay on the Immediate Data of Consciousness, translated by F. L. Pogson. New York: The Macmillian Company.

Blacking, John. 1967. Venda Children's Songs: A Study in Etbnomusicological Analysis. Johannesburg: Witwatersrand University Press 
Bregman, Albert S., and Stephen Pinker. 1978. "Auditory Streaming and the Building of Timbre." Canadian Journal of Psychology 32:19-31.

Brower, Candace. 1993. Memory and the Perception of Rhythm. Music Theory Spectrum 15:19-35.

Bourdieu, Pierre. 1977. Outline of a Theory of Practice, translated by Richard Nice. Cambridge: Cambridge University Press.

Clifford, James. 1988. The Predicament of Culture: Twentieth-Century Ethnography, Literature, and Art. Cambridge, Massachusetts: Harvard University Press.

Derrida, Jacques. 1973. Speech and Phenomena and Otber Essays on Husserl's Theory of Signs, translated by David B. Allison. Evanston, Illinois: Northwestern University Press.

Edie, James M. 1987. William James and Pbenomenology. Bloomington, Indiana: Indiana University Press.

Feld, Steven. 1982. Sound and Sentiment: Birds, Weeping, Poetics, and Song in Kaluli Expression. Philadelphia: University of Pennsylvania Press.

Giddens, Anthony. 1979. Central Problems in Social Theory: Action, Structure and Contradiction in Social Analysis. Berkeley: University of California Press.

- 1984. The Constitution of Society: Outline of a Theory of Structuration. Berkeley: University of California Press.

- 1993. New Rules of Sociological Metbod: A Positive Critique of Interpretive Sociologies, Second Edition. Stanford: Stanford University Press.

Handel, Stephen. 1989. Listening: An Introduction to the Perception of Auditory Events. Cambridge, Massachusetts: MIT Press.

$\rightarrow$ Hasty, Christopher F. 1986. "On the Problem of Succession and Continuity in Twentieth-Century Music." Music Theory Spectrum 8:58-74.

Husserl, Edmund. 1964 [1905]. The Pbenomenology of Internal Time-Consciousness, translated by James S. Churchill and edited by Martin Heidegger. Bloomington, Indiana: Indiana University Press.

Ihde, Don. 1976. Listening and Voice: A Pbenomenology of Sound. Athens, Ohio: Ohio University Press.

Jakobson, Roman. 1960. "Closing Statement: Linguistics and Poetics." In Style in Language, edited by Thomas A. Sebeok, 350-77. New York and Boston: John Wiles and Sons Incorporated and The Technology Press of Massachusetts Institute of Technology.

James, William. 1967 [1912]. Essays in Radical Empiricism. Gloucester, Massachusetts: Peter Smith.

$\rightarrow$ Kauffman, Robert. 1980. "African Rhythm: A Reassessment." Ethnomusicology 24:393-415.

$\rightarrow$ Keil, Charles. 1995. "The Theory of Participatory Discrepancies: A Progress Report." Ethnomusicology 39:1-20.

Lerdahl, Fred and Ray Jackendoff. 1983. A Generative Theory of Tonal Music. Cambridge, Massachusetts: MIT Press.

Lévi-Strauss, Claude. 1973. Tristes Tropiques, translated by J. and D. Weightman. London: Jonathan Cape.

Locke, David. 1987. Drum Gabu. Crown Point, Indiana: White Cliffs Media Company.

$\rightarrow$ Maceda, José. 1986. "The Concept of Time in a Music of Southeast Asia (A Preliminary Account)." Ethnomusicology 30: 11-53.

Marvin, Elizabeth West. 1991. "The Perception of Rhythm in Non-Tonal Music: Rhythmic Contours in the Music of Edgard Varèse." Music Theory Spectrum 13:61-78.

Merriam, Alan P. 1982. "African Musical Rhythm and Concepts of Time-Reckoning." In African Music in Perspective. New York: Garland Publishing, Incorporated.

Monson, Ingrid. 1995. Response. Ethnomusicology 39:87-89.

$\rightarrow$ Prögler, J. A. 1995. "Searching for Swing: Participatory Discrepancies in the Jazz Rhythm Section." Ethnomusicology 39:21-54.

Roeder, John. 1994. "Interacting Pulse Streams in Schoenberg's Atonal Polyphony." Music Theory Spectrum 16:231-249. 
Schachter, Carl. 1980. "Rhythm and Linear Analysis: Durational Reduction." In The Music Forum, Volume V, edited by Felix Salzer. New York: Columbia University Press.

. 1987. "Rhythm and Linear Analysis: Aspects of Meter." In The Music Forum, Volume

VI, Part 1, edited by Felix Salzer. New York: Columbia University Press.

Schutz, Alfred. 1967 [1932]. The Pbenomenology of the Social World, translated by George

Walsh and Frederick Lehnert. Evanston, Illinois: Northwestern University Press.

Small, Christopher. 1987. Music of the Common Tongue: Survival and Celebration in AfroAmerican Music. London: J. Calder; New York: Riverrun Press.

Smith, F. Joseph. 1979. The Experiencing of Musical Sound: Prelude to a Pbenomenology of Music. New York: Gordon and Breach.

$\rightarrow$ Smyth, David H. 1990. "Large Scale Rhythm and Classical Form." Music Theory Spectrum 12:236-246.

Stone, Ruth M. 1982. Let the Inside Be Sweet: the Interpretation of Music Event Among the Kpelle of Liberia. Bloomington, Indiana: Indiana University Press.

$\rightarrow-$. 1985. "In Search of Time in African Music." Music Theory Spectrum 7:139-148.

. 1988. Dried Millet Breaking: Time, Words, and Song in the Woi Epic of the Kpelle. Bloomington, Indiana: Indiana University Press.

Vander, Judith. 1988. Songprints: The Musical Experience of Five Shoshone Women. Urbana, Illinois: University of Illinois Press.

Walser, Robert. 1993. Running with the Devil: Power, Gender and Madness in Heavy Metal Music. Hanover, New Hampshire: University Press of New England.

$\rightarrow$ Wegner, Ulrich. 1993. "Cognitive Aspects of Amadinda Xylophone Music from Buganda: Inherent Patterns Reconsidered.” Ethnomusicology 37:201-242. 